San Jose State University

SJSU ScholarWorks

Master's Theses

Master's Theses and Graduate Research

1990

\title{
The effects of a massage therapy program on reducing the anxiety of college students
}

Diane Glaser

San Jose State University

Follow this and additional works at: https://scholarworks.sjsu.edu/etd_theses

\section{Recommended Citation}

Glaser, Diane, "The effects of a massage therapy program on reducing the anxiety of college students" (1990). Master's Theses. 3317.

DOI: https://doi.org/10.31979/etd.t39n-n8y7

https://scholarworks.sjsu.edu/etd_theses/3317

This Thesis is brought to you for free and open access by the Master's Theses and Graduate Research at SJSU ScholarWorks. It has been accepted for inclusion in Master's Theses by an authorized administrator of SJSU ScholarWorks. For more information, please contact scholarworks@sjsu.edu. 


\section{INFORMATION TO USERS}

The most advanced technology has been used to photograph and reproduce this manuscript from the microfilm master. UMI films the text directly from the original or copy submitted. Thus, some thesis and dissertation copies are in typewriter face, while others may be from any type of computer printer.

The quality of this reproduction is dependent upon the quality of the copy submitted. Broken or indistinct print, colored or poor quality illustrations and photographs, print bleedthrough, substandard margins, and improper alignment can adversely affect reproduction.

In the unlikely event that the author did not send UMI a complete manuscript and there are missing pages, these will be noted. Also, if unauthorized copyright material had to be removed, a note will indicate the deletion.

Oversize materials (e.g., maps, drawings, charts) are reproduced by sectioning the original, beginnirig at the upper lefi-hand corner and continuing from left to right in equal sections with small overlaps. Each original is also photographed in one exposure and is included in reduced form at the back of the book.

Photographs included in the original manuscript have been reproduced xerographically in this copy. Higher quality $6 " \mathrm{x} 9$ " black and white photographic prints are available for any photographs or illustrations appearing in this copy for an additional charge. Contact UMI directly to order.

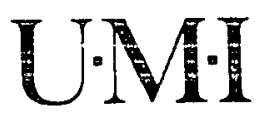

University Microfilms international

$\wedge$ Bell \& Howell Information Company 300 North Zeeb Road. Ann Arbor, MI 48106-1346 USA

$313: 761.4700 \quad 800 / 521.0600$ 

Order Number 1341668

The effects of a massage therapy program on reducing the anxiety of college students

\author{
Glaser, Diane I., M.S.
}

San Jose State University, 1990

Copyright (C)1990 by Glaser, Diane I. All rights reserved.

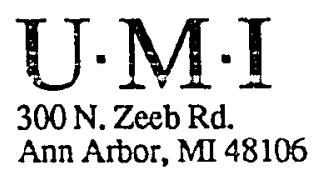



NOTE TO USERS

THE ORIGINAL DOCUMENT RECEIVED BY U.M.I. CONTAINED PAGES WITH SLANTED PRINT. PAGES WERE FILMED AS RECEIVED.

THIS REPRODUCTION IS THE BEST AVAILABL W COPY. 

THE EFFECTS OF A

MASSAGE THERAPY PROGRAM

ON REDUCING THE ANXIETY

OF COLLEGE STUDENTS

\author{
A Thesis \\ Presented to \\ The Faculty of the Department of Nursing \\ San Jose State University \\ In Partial Fulfillment \\ of the Requirements for the Degree \\ Master of Science \\ By \\ Diane Glaser
}

Augisst, 1990 
APPROVED FOR THE DEPARTMENT OF NURSING

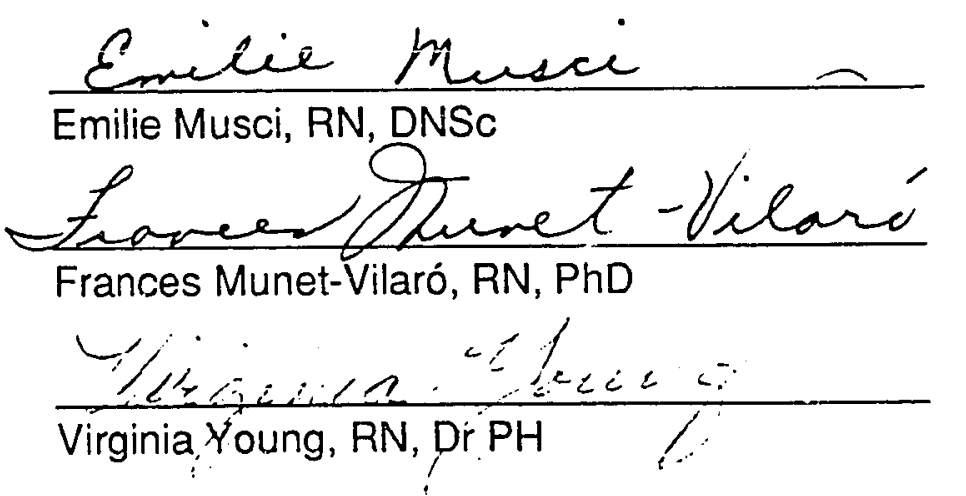

APPROVED FOR THE UNIVERSITY

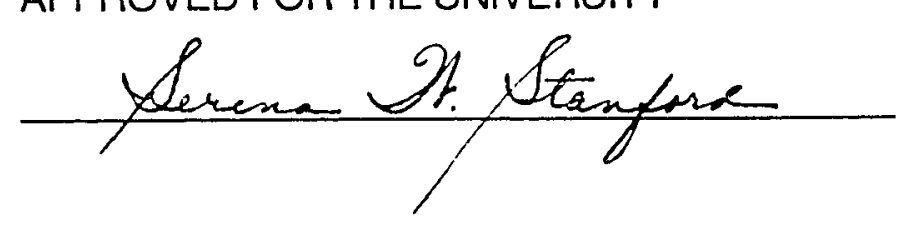




\section{ACKNOWLEDGEMENTS}

To my ilusband and daughter for their support and patience.

To my graduate advisor, Dr. Emilie Musci,

for her assistance and encouragement,

and to the Massage Practitioners at Foothill College

for their assistance and enthusiasm.

Funding for the Study was provided by the Associated Professional Massage Therapists and Bodyworkers, Inc. 


\section{ABSTRACT \\ THE EFFECTS OF A MASSAGE THERAPY PROGRAM \\ ON REDUCING THE ANXIETY CF COLLEGE STUDENTS}

by Diane Glaser

A campus-based Massage Therapy Program was implemented at a South San Francisco Bay community college to provide an innovative means for stress reduction for the student population. The purpose of this study was to evaluate the program's effectiveness in reducing anxiety, a negative aspect of stress, in students who participate in the program. Two groups of students were selected for the quasi-experimental study. One group consisted of 25 students who were participating in the massage program. The comparison group consisted of 33 students enrolled in two general education courses and who were not participating in the program. Participants from both groups were pretested and posttested using the State-Trait Anxiety Inventory Self-Assessment Questionnaire. In comparing gain scores of both groups, results indicated a significant reduction $(\underline{t}=4.51, \underline{p}<.001)$ in anxiety in the massage participants when compared to the group of general students. 


\section{TABLE OF CONTENTS}

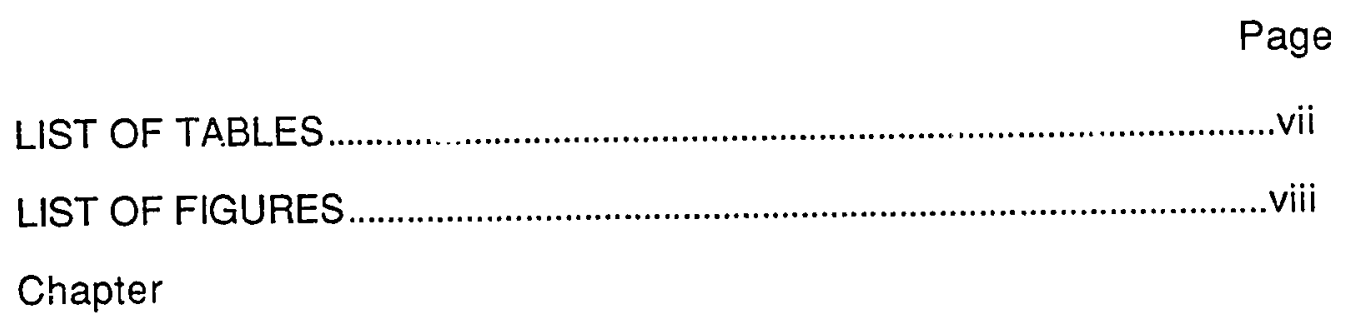

1. INTRODUCTION ....................................................................... 1

Background of the Problem .......................................................... 1

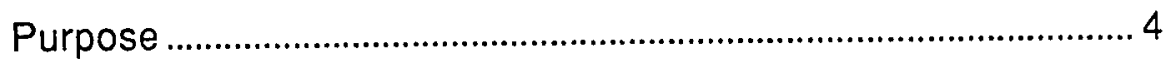

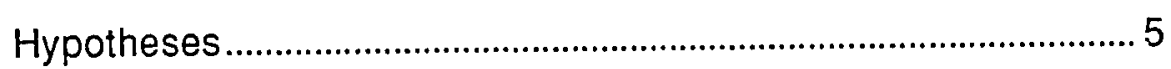

Definition of Terms....................................................................... 5

Research Design ...................................................................... 7

Data Collection Instrument......................................................... 7

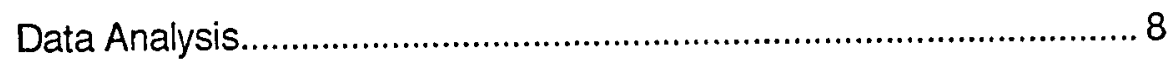

Scope and Limitations........................................................ 8

2. CONCEPTUAL FRAMEWORK AND REVIEW

OF RELATED LITERATURE................................................. 11

Conceptual Framework ............................................................... 11

Review of the Literature ............................................................... 16

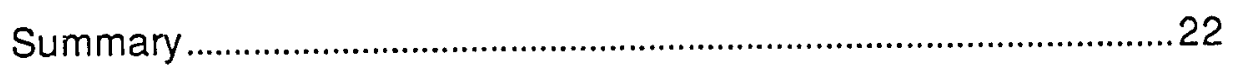

3. RESEARCH DESIGN AND METHODOLOGYY .............................24

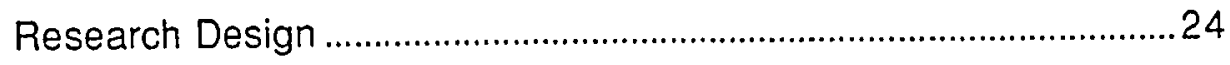

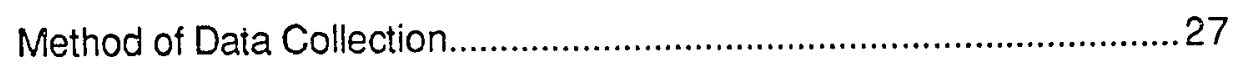


Page

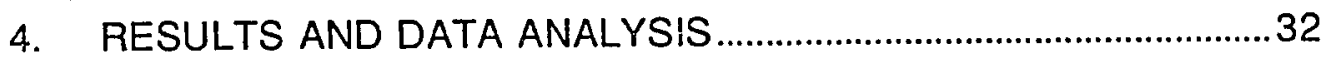

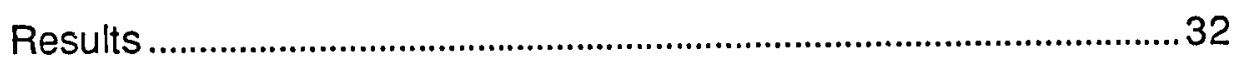

5. CONCLUSIONS AND RECOMMENDATIONS...............................40

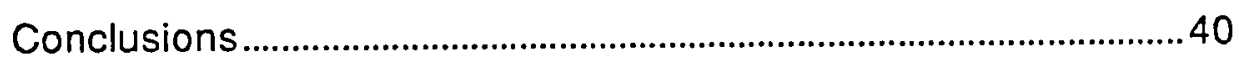

Recommendations........................................................................ 41

Implications for Nursing Practice .....................................................42

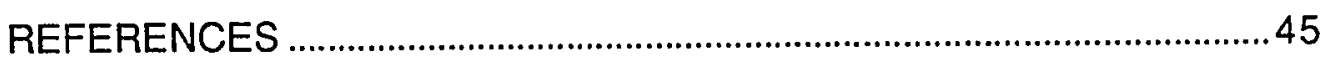

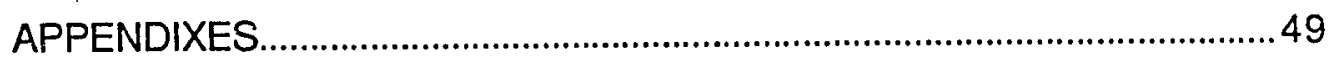

A. Sample of State Trait Anxiety Inventory ...................................50

B. Means, Standard Deviations and Alpha

Coefficients for College Students .......................................52

C. Approval by Human Subjects Institutional

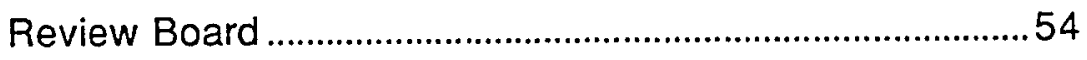

D. Foothill College Approval by Vice-President

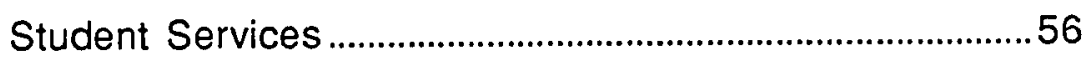

E. Consent Form for Experimental Group....................................58

Consent Form for Massage Group ...........................................58 


\section{LIST OF TABLES}

Table Page

1. Age, Sex and Work Status of Participants ...............................33

2. Experimental and Control Group Mean

Trait Anxiety Scores ...........................................................36

3. Experimental and Control Group Mean

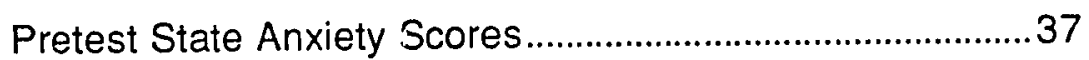

4. Experimental and Control Group Mean

Posttest State Anxiety Scores ................................................39 


\section{LIST OF FIGURES}

Figure

Page

1. Neuman's Format for Primary Prevention/

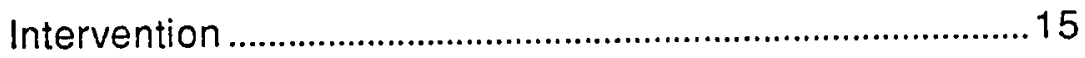




\section{Chapter 1}

\section{INTRODUCTION}

Much research has been devoted to the factors that affect human health. One of these factors, that of stress, has been perhaps one of the most widely studied subjects. Stress has been defined in physiological, psychological, positive and negative terms, and has been linked to many physical and mental disorders. Coronary heart disease, hypertension, headaches, impaired disease resistance, anxiety disorders and depression have all been attributed to an individual's response to stress, greatly affecting human health today.

The focus of this study is on a psychological aspect of stress, manifested by anxiety, in the college population. Lazarus (1963) states that stress complicates a person's ability to resolve conflicts. The negative aspect of stress manifested by anxiety interferes with thinking and problem solving and has been demonstrated to hinder atiention span anư the learning process $(\hat{p} .11)$. The concept of anxiety as a result of stress, then, bears important implications for the academic environment.

\section{Background of the Problem}

Twelve million students are currently enrolled in U.S. colleges and universities, representing $5 \%$ of the American population (Guyton, Corbin, Zimmer, O'Donnell, Chervin, Sloan \& Chamberlain, 1989). In addition to the younger, more conventional full-time student, colleges are seeing an iricreased 
number of older first-time and returning students. All students attending college are potentially at risk for a number of health concerns. Family, financial and career responsibilities are compounded by academic responsibilities increasing the risk of overextending personal resources. By providing an environment conducive to learning and behavior change, colleges could be in a good position to influence long-term health and personal habits to improve th: well-being of this significant segment of society.

Mental health concerns related to stress have been identified as an important campus healîh problem (Guyton, et al., 1989). In addition to schocil responsibilities, the younger students are coping with (a) the pressure to achieve, (b) the fear of failure, (c) the lack of social support, and (d) low self-esteem (Guyton, et al., 1989). Eighteen to 22-year-olds are experiencing a difficult development stage. Many young adults are beginning to see alternatives to their parents' beliefs and become confused. Peer pressure is heavy in the lifestyle of the college students and includes high level activity and poor eating and sleeping habits. These habits predispose the students to a number of health concerns (Freiberg, 1979, p. 348). Also, there is increased exposure to drugs and alcohol during this developmental period as students begin to break from parental restrictions. The U.S. Department of Health and Human Services (1987) reports that $17 \%$ of college students use cocaine, $45 \%$ have occasions of heavy drinking, and $25 \%$ are daily smokers. All of these 
factors contribute to a stressful lifestyle and place these students at high risk for stress-related problems.

The 18 to 22-year-old full-time student does not, however, represent the majority of enrolled college students. Guyton et al. (1989) report that only 2 of the 12 million college students nationwide fit this description. With 10 million older, part-time, married and working students attending college, a different set of risk factors predisposing these students to stress-related disorders becomes apparent. Complex factors such as (a) family/parental obligations, (b) economic constraints, and (c) career responsibilties are added to the stresses of school responsibilites. At a time when college students are beginning to assume new responsibilities for themselves economically, emotionally and physically, they are exposed to few acceptable coping mechanisms or activities.

The mission of the Community Coliege Health Services is to "facilitate the educational experience of the students through the promotion of their physical and emotional well-being" (Health Services Ȧssociation of California Community Colleges, 1987, p. 1). In an effort to provide acceptable coping activities, a massage therapy program was implemented. The direct intent of this program was to provide students with an acceptable stress management activity. An indirect intent was to expose this population to massage as an alternative to other (unhealthy) coping behaviors such as smoking, and using drugs and alcohol (N. Kitajima, personal communication, March 7, 1989). 
The massage program may be recognized as creative and a new innovation. The need for evaluation of the value of this nealth promotion program is critical. Legitimacy of the massage program is being questioned in terms of its appropriateness on the college campus and in terms of its health promotion effects. As the cost of health care continues to increase (U.S. Department of Commerce, 1988), evaluation of health promotion programs such as this one is mandatory for survival.

Purpose

The massage therapy program that was implemented at a community college was a result of a needs identification for a stress reduction program. After consideration of all the factors indicating a need for a stress reduction program, which included (a) developmental stage, (b) incidence of accidents and vioient crime, (c) prevalence of substance abuse, and (d) family, financial and career constraints, the Health Services Department proceeded with a hands-on preventative approach to stress. No other similar program exists, to the knowledge of this investigator, making this evaluation difficult to compare with others. Not only are studies on the effectiveness of massage inconsistent, studies on stress reduction as well are difficult to analyze (Kaufman, 1964; Longworth, 1982). Yet the results of several studies indicate that the management of stress remains a priority health issue among college educators and students (Hendricks \& Young, 1986; Guyton, et al., 1989; and Foothill 
College Health Services, 1989). Thus, it is clear that an evaluation study in this area is indicated.

The purpose of the study was to determine the effectiveness of an existing massage therapy program for students attending a community college.

Specifically, this study looked at the program's effect on the students' emotional well-being as perceived by the massage participant. Stress was measured as degrees of anxiety in the experimental (massage) group and was compared to a similar group of students not participating in the massage program.

Hypotheses

The hypotheses tested were: 1) students participating in a massage therapy program arid attending classes will demonstrate lower anxiety levels atter massage than before massage, and 2) students enrolled in courses and not participating in the massage program will not demonstrate a significant change in anxiety levels, as measured by the State Trait Anxiety Inventory, Self-Assessment Questionnaire.

\section{Definition of Terms}

The following terms are defined for the purpose of the study:

\section{Conceptual Definitions:}

1. Community College Students are aduits 18 years of age and older currently enrolled and attending college courses.

2. Stress is a "relationship between the person and the environment that 
is appraised by the person as taxing or exceeding his or her resources and endangering his or her well-being" (Lazarus \& Folkman, 1984, p. 19).

3. Massage is a "group of systematic and scientific manipulations of body tissue, performed by hand, for the purpose of affecting tha nervous and muscular systems and the general circulation" (Krusen, 1966, p. 360).

4. Anxiety is an emotional manifestation of a stress state perceived as a threat. Two related concepts of anxiety, state and trait, clarify this term further. State anxiety is a response to the threat (Lazarus, 1966) and is "characterized by subjective feelings of tension, apprehension, nervousness and worry" (Spielberger, 1983, p. 1). Trait arixiety refers to an individual's predisposition or proneness to anxieiy (Spielberger, 1983, p. 1).

\section{Operational Definition}

1. Massage Therapy Program is a program currently implemented at a local community college. One-hour whole body massages are offered to students during campus hours on an appointment basis through the Student Health Services. Massages are performed by Certified Massage Practitioners, who utilize a balance of Swedish and Esalon Oil Massage. Students are limited to a maximum of three massages per quarter. The students pay a co-payment of $\$ 10.0$ for their first massage of the quarter and $\$ 15.00$ each for the remaining two massages for the quarter. The student health fee that all students pay subsidizes the salaries of the Massage Practitioners. 


\section{Research Design}

This research was quasi-experimental and utilized a non-equivalent control group design. The independent variable was a one-hour body massage and the dependent variable was the students' perceived anxiety level. It was anticipated that 30 participants would be in the experimental and control groups, for a total sample size of 60 . Both groups were voluntary convenience samples.

One antecedent variable to be controlled was previous exposure to massage. Longworth (1982) ackowledged in her study that cortical habituation to massage may reduce muscle tension. She states, "the role of the cortex appears to be related to its ability to remember previous experiences; that is, it can interpret whether a stimulus is neutral or life threatening" (p. 50). To control this bias, and possible acclimation to massage, the researcher eliminated potential participants who had had more than one massage in the past six weeks. The existing massage program offered three massages per quarter per student. This study began when most students were receiving their first or second massage for the quarter. Students participating in the study were pretested and posttested on either their first or second massage only.

\section{Data Collection Instrument}

The instrumerit used to measure the anxiety level of students was the State-Trait Anxiety Inventory Self-Evaluation Questionnaire (STAI) 
(Spielberger, 1983) (Appendix A). One set of questions on the STAl measure State Anxiety, another set assesses Trait Anxiety. The purpose of the Trait Scale was to establish the similarity or difference between the two groups. This instrument was easy to administer and score. In addition, the test has been used extensively with the college population, and standard scores for students are available.

\section{Data Analysis}

The statistical techniques employed in this study were the parametric f-test comparing the gain scores of the two groups. In analysis, the means and standard deviations of test scores of the two unrelated (and independent) groups were compared. Scoring of the STAI was done according to the guidelines in Manual for the STAI (Spielberger, 1983). Also, comparisons were made with the control group and experimental group against the published norms provided in the STAI manual. Means, Standard Deviations and Alpha coefficients for male and female college students were published in the manual (Appendix B). Demographic data was collected and descriptive statistics included age, sex, and working status.

\section{Scope and Limitations}

The scope of the project was to obtain anxiety scores from all students who volunteered to be participants and who qualified for this study during the months of January through March 1990. 
One limitation of this study was the inability to prove a clear cause and effect relationship, since this was not a true experiment. LoBiondo-Wood and Haber (1986) state:

In comparison to the true experimental design, quasi-experiments are quite similar in their utilization. Both types of designs are used when the researcher is interested in testing cause and effect relationships. However, the basic problem with the quasi-experimental approach is a weakened confidence in making causal as sertions (p. 121.)

In this study, randomization was not possible. The sample was not chosen randomly, nor were subjects randomly assigned to the experimental and control groups. This reduced the strength of a cause and effect relationship.

As a resuit of the lack of randomization, another limitation in this study was the use of the non-equivalent control group. The degree of difference or similarity between the two groups was unknown, and the two groups could not be considered equal. The effect of this limitation was lessened by comparing the trait scores of the STAI of both groups in the study. This allowed the researcher to compare the equivalence of the two groups prior to the manipulation of the independent variable.

A third limitation of the study resulted from using a self-evaluation questionnaire and an assumption that the students' responses were accurate. LoBiondo-Wood and Haber (1986) report "people are known to respond to questions in a way that makes them look good" (p. 161). This social desirability response of students presented a weakness in the design, yet using 
questionnaires required the researcher to assume that the respondents were telling the truth.

A final limitation resulted as a consequence of selection bias, an intervening variable. When individuals made the decision to volunteer to participate in the study, analysis of the effectiveness of the manipulation was limited because the investigator did not know what other intervening variables were involved that could have affected the results. Motivation, prior knowledge of the subject and life experiences were factors to be considered in the analysis. Therefore, the findings from this study can only be generalized to this community college population who were interested in or motivated to be exposed to a hands-on stress reduction program. 


\section{Chapter 2}

\section{CONCEPTUAL FRAMEWORK AND REVIEW OF RELATED LITERATURE}

\section{Conceptual Framework}

Neuman's Systems Model for evaluating nursing problems provided the conceptual framework for this study. Systems theory, on which Neuman bases her model, helped to organize concepts and problems allowing identification of the interrelatedness of several subparts and subsystems within the whole system. For example, nursing would be placed as a subsystem under the larger system, or category of health care. Nursing, then, is categorized further into two components of nursing education and nursing practice. Systems theory places all parts of a system into a larger system where their interrelatedness and interdependence can be more fully understood (Neuman, 1982, p. 8).

Systems theory allows for increased growth and complexity. It is continually evolving from states of lesser and greater organization and balance. When a particular system is in a temporary state of balance, it is said to be in a "steady state." One goal of any system is to continually develop toward this steady state (Neuman, 1982, p. 9).

Systems theory, used by Neuman, provided a unifying focus for understanding the relationship between man and the environment. In this model, man is viewed as a highly complex biopsychosocial being engaged in a dynamic process with his internal and external environments. Man is in a state 
of optimal health when all his needs are met. Conversely, illness is defined as a state of disrupting needs which are yet to be satisfied. When the balance of illness/wellness has been restored, homeostasis (steady state) has been regained and man has regained his optimal state of health (Neuman, 1982, p. 10).

Using Neuman's Systems Model, the goal of nursing is to utilize the process of needs assessment to determine the needs, problems or desires of the target system or subsystems to promote the highest level of health. A target system may be an individual or group (Bevis, 1982, p. 103). This model, then, extends beyond the illness, or medical model, and includes the concept of problem finding and prevention. With wellness incornorated irito the model, it is well suited for use in a community health education setting.

Three primary concepts, taken from Neuman's model, formed the conceptual framework for this study. The first of these is stress. Consistent with systems theory, which places healtin and wellness on a continuum, Lazarus and Folkman (1984) view stress as a dynamic relationship between the individual and the environment. Stress requires the individual to evaluate the current status of the relationship using two processes: cognitive appraisal and coping. During the primary cognitive appraisal process, the person evaluates the extent of the stressful stimuli as either a threat, a challenge or harmful. Then the individual appraises his/her ability to cope with the stressful stimuli. This is the 
secondary cognitive appraisal process. Coping is the process by which the individual accommodates, or adjusts, in order to attain/maintain homeostasis in the person-environment relationship. Stress results when an individual, having appraised a situation, determines that the energy required to cope with the situation exceeds resources and that it is a threat to well-being (Lazarus \& Folkman, 1984, p. 19).

Stressors, the second concept, are events and/or problems perceived by the individual as threatening. Stressors are "tension-producing stimuli with the potential of causing disequilibrium, situational or maturational crisis" (Marriner, 1986, p. 35). Neuman has adapted the term stressors to encompass internal and external events. She considers stressors to be: (a) Intrapersonal, within the individual; (b) Interpersonal, between one or more individuals; or, (c) Extrapersonal, occurring outside the individual (Neuman, 1982, p. 14).

Neuman's Systems Miodel is represented by a series of circles around a central core (Figure 1). The central core is an individual's basic survival structure and includes the mechanics for the maintenance of temperature, genetic response patterns, and the strengths and weaknesses of the various body parts or organs. The broken rings around this core vary in size and. distance from the center and are "flexible lines of resistance" (Marriner, 1986, p. 315). These are internal factors that assist the individual in protection against stressors. An example of this is the immune system building a defense against 
disease. The outer solid circle is the normal line of defense. This circle represents the normal state of wellness of the individual or a state of adaptation that is normal for that particular individual. The flexible line of defense, the outer broken ring, is the first line of defense the individual has for protection against stressors. It is dynamic and unique to each individual. When considering individual differences, this model acknowledges that what might be appraised as threatening to one person may not be to another. The reaction to the varying threats to the lines of defense, also, depends upon the individual's vulnerability and coping ability. It is this line of defense that forms the foundation for this study. Interventions, by nursing, must occur when a stressor is either suspected or identified, before it is allowed to cross the flexible line of defense. This nursing action is known as primary prevention. The goal of primary prevention is to strengthen the flexible lines of defense surrounding an individual, group or community (Neuman, 1972). 


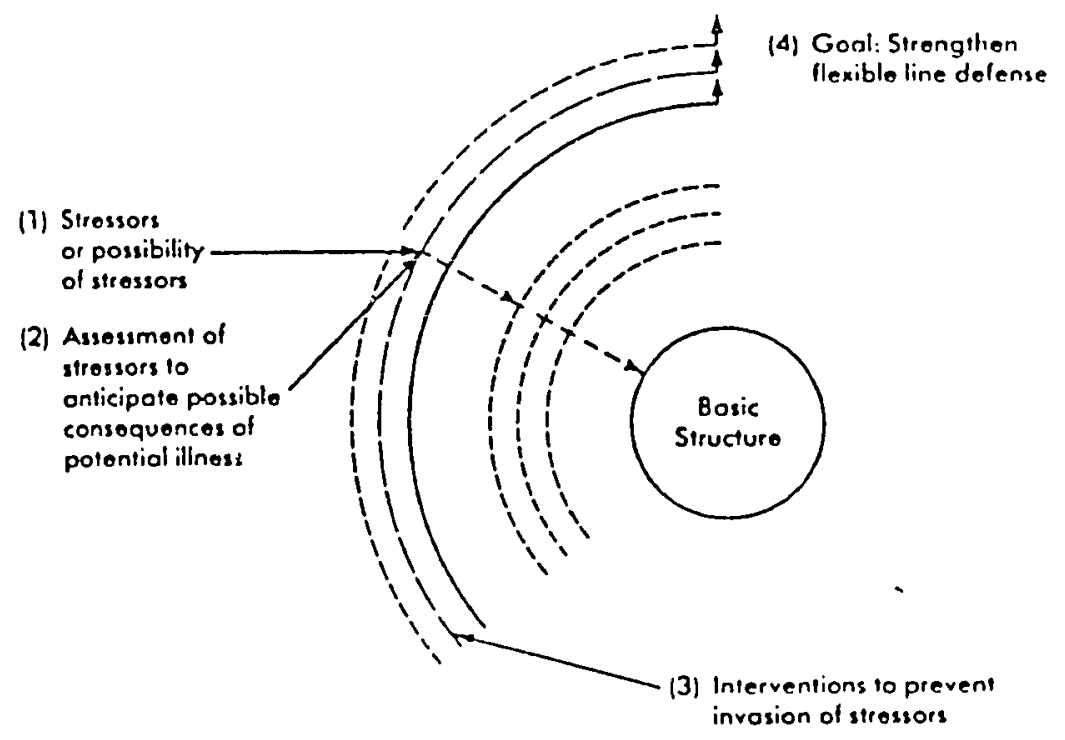

Figure 1. Neuman's format for primary prevention/intervention.

Note: From Nursing theorists and their work (p. 319) by A. Marriner, 1986, St.

Louis, Missouri: The C.V. Mosby Company. Copyright 1986 by the C.V. Mosby Company. 
Review of the Literature

The goal of Neuman's systems theory is consistent with the goal of the community college health services' philosophy. The identification of priority areas in health promotion and disease prevention have been the focus of the American College Health Association (ACHA) since 1985. A task force was formed at that time to outline the health objectives of the nation in higher education as a result of the Surgeon General's Report on Health Promotion and Disease Prevention (Chervin, Slcane, Gordon \& Gold, 1986).

The task force recognizes college students as a population in transition. Health practices are being questioned; therefore, colleges and universities can have a significant impact on students' decision making in regard to their present and future health status. The identification of potential stressors in this population and making recommendations for implementing programs for intervention will strengthen the health status in a significant portion of the young adult population in the United States (Chervin, et al., 1986).

As a result of the study, control of stress was identified as a priority (Chervin, et al., 1986). Concurrently, other studies were being conducted to determine what students identified as their needs. Hendricks and Young (1986) surveyed students to assist the college in determining the course content for their health education. The results of this study showed that stress was among the topics in which the students expressed the highest interest. In other words, 
not only did the task force, made up of members of college health services personnel, identify stress as a priority health concern, but students themselves showed a high interest in acquiring more information on this topic.

The need to improve the long-term health habits of college students by assisting them in finding acceptable coping activities is apparent. Another consideration, also, is the immediate consequence of the effect of anxiety on academic achievement. Spielberger (1962) conducted a study investigating the effect of anxiety on college grades. Recognizing the potential for anxiety in this population, Spielberger hypothesized that students with a lower level of anxiety would perform academically higher than students with a high level of anxiety. Results indicated that, with the exception of the very superior students, the effect of anxiety on grade point average was detrimental. Students in the middle ranges of ability with high anxiety scores academically performed at a lower level than students with low anxiety scores.

Stressors have been identified as potential threats to college students (Chervin, et al., 1986). Health promotion programs are needed to teach new health practices and to strengthen students' defense(s) against stress reactions. The goal of any program is to assist the students in finding a suitable activity that fits their individual needs in order for them to benefit from this newly acquired health practice during their college years and beyond. 


\section{Historical Review of Massage and Related Literature}

Massage is considered to be among the oldest of all treaiments used by man. Records dating as far back as 3,000 years were made by the Chinese documenting its use. The ancient Hindus, Persians and Egyptians used forms of massage for some ailments and Hippocrates wrote papers recommending the use of rubbing and friction for joint and circulatory problems (Krusen, 1966). The Chinese books on massage were translated ir.to French about two hundred years ago, which accounts for the French terminology common to massage texts today. Peter Ling (1776-1839), a Swedish fencing master, systematized the massage techniques which now form the basis for massage used in current physical therapy practice (Tobias, 1984).

Today, massage is an accepted part of many physical rehabilitation programs. Krusen (1966) lists many conditions in which massage is indicated. These include any condition in which relief of pain, reduction of swelling, or mobilization of contracted tissue is desired. Fractures, dislocations, joint injuries, sprains, strains, and tendon and nerve injuries are all conditions that could benefit from massage at certain stages of recovery. Some degenerative diseases such as multiple sclerosis and other chronic conditions such as low back pain, arthritis and bursitis, may also benefit from massage.

Many physiological benefits of massage have been documented. These include (a) the stimulation of peripheral receptors in the skin with, (b) a reflex 
response (via the spinal chord and brain) of muscle relaxation, (c) arteriole dilation or constriction, (d) local increases in capillary diameter, and (e) increase in blood and lymph flow (Krusen, 1966). Claims that massage produces a psychological effect of general relaxation, that it reduces stress and relieves pain are not consistently documented in the literature. Most importantly, the mechanism by which massage achieves these conditions is the main source of controversy surrounding the psychological stress reduction benefits of massage.

Several studies have attempted to determine the mechanism by which massage helps patients achieve psychological relaxation and pain relief. One study (Day, Mason \& Chesrown, 1987) looked at the effects of massage on serum endorphins and concluded that a complete back massage does not induce a significant change in serum endorphin levels as was hypothesized. In 1964, Kaufman investigated the possible relationship between the autonomic system responses and the relaxation, stress reduction effect of back massage. Again, her findings were inconclusive, and she did not find a strong relationship between autonomic (sympathetic) nervolis system enervation as a result of massage in producing a general state of relaxation.

In a similar study, Longworth (1982) investigated the psychophysiological effects of slow stroke back massage (SSBM). She compared the perceived staie anxiety and stress of participants with (a) varying massage times and, 
(b) heart rate, (c) diastolic blood pressure, and (d) skiri temperature. A 3-minute massage produced significant increases in systolic blood pressure and non-significant decreases in the remaining physiologic measurements. These findings indicate autonomic arousal as the mechanism in massage. However, the 6-minute massage showed significant increases in mean heart rate. Systolic and diastolic blood pressure decreased and galvanic skin response increased; skin temperature remained stable. Longworth states: "These trends were not significant but are consistent with lower arousal of the autonomic and psychoemotional components. This trend supports the view that habituation to the tactile sensation of slow stroke back massage occurs" (1982, p. 58). An interesting finding in this study was that the pre- and post-massage STAI scores did not correlate with the psychoemotional indices of mean galvanic skin response and skin temperature. This suggests that other mechanisms of arousal and relaxation may produce different responses. Longworth recommended replication of the study with use of a control group to. demonstrate consistency and support her presumption that massage works through tactile habituation.

In reviewing and comparing results of studies on massage, one major difficulty encountered is the lack of consistent parameters. Each study described individual parameters to measure levels of arousal and the effects of relaxation techniques. The studies also differ in the terminology used to define 
such terms as arousal, relaxation, stress, and massage. The effects of massage will vary depending on the type of stroking used. The variation in the results of the study may be explained in part by the fact that some subjects had disease conditions, others did not. This lack of consistency and replication in operational procedures makes it difficult to compare findings of different studies.

The perceived stress reduction by the subject is one result, however, that does seem to be common to several studies. Kaufman's (1964) study found that some participants "perceived comfort and relaxation without significant changes in autonomic activity" (p. 54). Overall, the verbal response of participants' perception of massage was "almost entirely of a strongly positive nature" (p. 54). The results of the STAI of Longworth's (1982) study indicated that the "slow stroke back massage was perceived as relaxing by the subjects" (p. 56). She also found that the STAI scores did not significantly correlate with the other indices of mean galvanic skin response and skin temperature. This further supports the conclusion that even though the mechanism by which massage promotes relaxation and stress reduction remains unclear, the majority of subjects participating in these studies perceive a definite stress reduction or relaxation effect. 


\section{Summary}

Studies on the mechanisms and the psychological effectiveness of massage have revealed numerous inconsistencies. The results of studies on stress reduction have proven difficult to compare. One possible explanation for the conflicting research findings, besides the lack of consistent parameters and terminology, may be due to researchers investigating psychological and physical actions of massage simultaneously, although this is necessary for research. There are few studies dealing solely with the psychological effects of massage and a "well" population. Most deal with multiple measures, both psychological and physical. The effectiveness of a stress management program utilizing massage may best be established by studying, at least initially, a single psychological measure. This study of a single pyschological measure will provide a reliable knowledge base for further research to build upon.

Another explanation for conflicting research may be the differences of individual perceptions. Individual differences might be a variable responsible for the lack of correlation between perceived stress reduction and physiologic measurements. Each person is a unique individual with different feelings, fears, personalities and methods of coping with stress. What is stressful to one person may not be to someone else. In Systems Theory, individual differences are acknowledged by Neuman. Lazarus and Folkman's (1984) definition of the 
stress appraisal process recognize the importance of individual perceptions (p. 46). It is the concept of individual differences that has led this researcher to investigate an individual's perception of his/her current status with regard to stress and the internal and external environments. 


\section{Chapter 3}

\section{RESEARCH DESIGN AND METHODOLOGY \\ Research Design}

According to LoBiondo-Wood and Haber (1986, p. 102), the "overall purpose of the research design is twofold: to aid in the solution of research questions, and to maintain control." For this study the pretest-posttest quasi-experimental design was chosen utilizing a non-equivalent control group, because randomization was not feasible. However, other methods of control over potential threats to internal validity compensated for the inability to randomize. Gathering data at the time of the pretest allowed the researcher to establish the initial similarity of the two comparison groups. In this study, it was important to demonstrate that the state and trait levels of anxiety of the participants in each group were similar.

\section{Approval for the Study}

The research protocol and instrument were submitted and reviewed by the Human Subjects Review Board of San Jose State University (Appendix C). The research proposal was submitted to the Vice-President of Student Affairs at Foothill College (Appendix D). The proposal was approved prior to data collection.

\section{Setting}

The setting consisted of a two-year community college located in Los Altos 
Hills, California. Foothill College is part of the Foothill-De Anza Community College District serving Santa Clara County and surrounding areas.

The population of Santa Clara County is approximately 1.4 million. The mean household income is $\$ 45,000$ and is expected to increase $24 \%$ by the year 2005. The number of persons per household was 2.78 in 1985 and is declining (County of Santa Clara, 1988). The inferences apparent from these statistics (increased cost of living and income, and decreasing family size) are reflected in the demographic profile of the student population. The majority of students at Foothill College are female, between the ages of 25-49, and are attending the college for either an AA/AS degree or for improved job skills (California Community Colleges, 1987).

Foothill College's Massage Therapy Program is operated through the Student Health Services Department. Flyers placed around campus advertised the ongoing program, and only provided information including cost for the one-hour body massage, types of massage used, and who students were to contact for further information. The flyers did not include statements regarding any possible psychological or physiological benefits of massage. All students who were interested came to the Student Heaith office for additional information and made appointments. At this time, students paid for their massage(s) and completed questions which provided the massage therapist with demographic data and health status information. 
The three Certified Massage Practitioners who performed the massages on students were all graduates of the same massage therapy school. At the time of the massage appointment, the massage practitioners met with the student briefly to give him/her an opportunity to ask questions and establish rapport with the therapist. This process also allowed the therapist to clarify any concerns he/she had regarding information on the student's agreement. At this point, the procedure for the massage was explained to the student, who then was given privacy to undress to his/her level of comfort. Students were instructed to lie down on the massage table and cover themselves with a large towel. The therapist then returned and proceeded with a one-hour body massage conducted in a professional manner in a warm, comfortable and confidential room in the Student Center, on campus.

\section{Sample}

The students selected for participation in either the massage or control group were drawn from two different convenience populations. The massage group consisted of students who had recently arranged for a massage through the Student Health Services. Specific criteria for inclusion in the siudy were that students be at least 18 years old, be able to read, write and speak English, and be receiving either their first or second massage for the quarter.

The second group of students selected for participation in the study consisted of students currently enrolled in general education courses. The 
specific criteria for inclusion in the study for these students were that they be able to read, write and speak English, be at least 18 years old, and not be participating in a regular massage program. Two classes were required in order to obtain a large enough sample and to ensure a homogeneous representation of community college students. One day-time general education course (Guidance) and one evening class (General Psychology) were used for data collection.

\section{Method of Data Collection}

The process of data collection for this study involved two phases. The first consisted of the selection of willing students enrolled in the general education classes. The second part involved contacting individual massage students for agreement to volunteer for the study. The State and Trait Anxiety of these two groups of students were measured, using the STAI. Approximately one week later, the State Anxiety posttest was administered to both groups. The control group received no intervention during this period and the massage group participants received their regularly scheduled massage prior to administration of the posttest.

\section{State Trait Anxiety Inventony}

The anxiety level of the participants was the dependent variable to be measured. The tool used to measure the anxiety level of students was the State-Trait Anxiety Inventory, Self-Evaluation Questionnaire (STAI). The STAI 
is a self-report scale by which students rate themselves on a four-point scale of increasing intensity. State anxiety measures

an emotional state at a given moment in time and at a particular level of intensity. Anxiety states are characterized by subjective feelings of tension, apprehension, nervousness and worry and by activation or arousal of the autonomic nervous system (Spielberger, 1983, p. 1).

Trait ainxiety is described by Spielberger (1983) as

relatively stable individual differences in anxiety-proneness, that is, the differences between people in the tendency to perceive stressful situations as dangerous or threatening and to respond to such situations with elevations in the intensity of their state-anxiety reactions (p. 1).

The State-Trait Anxiety Inventory was chosen as the best suited tool in measuring anxiety in this student population for several reasons. This tool has a high test-retest reliability for the Trait Anxiety which is .73 to .86 . Internal consistency was measured using Cronbach alpha coefficients. The State Anxiety is .91 to .93 ; Trait Anxiety is .90 to .91 for college students (Spielberger, 1983). It is a published tool, widely used with many populations including college students, and it has been used in studies on massage and perceived stress reduction (Longworth, 1982; Tobias, 1984), adding to its reliability as an accurate indicator of anxiety. Because this tool measures Trait Anxiety, the investigator was able to compare the two groups' predisposition to anxiety during the pretest. This comparison established both groups as homogeneous representative samples of college students.

The STAl is easy to administer. The test consists of 40 items and 
participants rate their responses on a 4 point scale. The lowest score possible is 20 , indicating the lowest level of anxiety. The highest score possible is 80 , indicating the highest level of anxiety. The test takes approximately 15-20 minutes to complete with minimal directions. The manual includes directions for writing a computer program for ease in scoring and using statistical analysis. The test can be scored manually.

\section{Procedure for the Study}

The process for conducting this study was as follows: Beginning February 1, 1990, the investigator checked the massage appointment book in the Health Services office 3-4 times per week and contacted students who had made appointments for either their first or second massage. The investigator explained the purpose of the study, which was to evaluate the effectiveness of the massage therapy program. There was no mention of stress, anxiety or the measurement of either. The students were informed that a grant had been obtained allowing students to be paid $\$ 5.00$ each for participating. If the student agreed to participate, an iridividual meeting on campus was scheduled to obtain written, informed consent (Appendix E) and to administer the pretest. The site of the pretest was in a quiet room where the student could complete the questionnaire undisturbed. Instructions on completing the pretest according to manual directions were given. After completing the pretest, students were instructed to attend their massage appointment as scheduled and that the 
massage therapists would be administering the posttest following their massage. At the time of the posttest, the students would receive $\$ 5.00$. Instructions were also provided regarding receiving the results of the study through the Health Office (in May, 1990).

The process for obtaining students to participate in the control group was: One instructor from a daytime General Education Guidance class and one instructor from an evening Introductory Psychology class were contacted to discuss the invitation for their respective students to participate in the study. The instructors obtained prior verbal agreement from the students for the researcher to present the study, describe its purpose, and ask for students wishing to participate. Written consent of those students agreeing to participate was obtained. The same description of the study was given to the control group. The students were instructed to complete the pretest (according to manual directions). They were informed when the posttest and $\$ 5.00$ would be given. Posttests were administered within one week. Directions were given regarding obtaining results of the study.

All students participating in the study were assured of anonymity by the following procedure: No names were written on the tests. All tests and consents were numbered, and the numbered posttests were matched up with the numbered pretests while still attached to the consents. This insured that the same student received corresponding numbers from the pretest and posttest. 
The consents were separated from the pretest prior to scoring.

Voluntary participation was reinforced verbally. Also, students were informed that refusal to participate or withdrawal from the study at any time was acceptable without any repercussions from Foothill College or San Jose State University. Finally, to minimize the effect of social desirability, students were asked to complete the questionnaires as honestly and truthfully as possible.

\section{Risks and Benefits}

The risks and benefits of participating in this study were presented to the students. One possible risk included any discomfort felt as a result of responding to the questionnaire as truthfully as possible. Students were given the option to withdraw if they were concerned with this effect. The benefits of participating in this study included an increased exposure to a health promotion program on campus and that answering the questions might stimulate thinking and insight into their individual emotions. 


\section{Chapter 4}

\section{RESULTS AND DATA ANALYSIS}

This chapter describes the data and the procedures used to analyze the data. The purpose of the analysis was to test the hypothesis that a massage therapy program would be effective in reducing the anxiety level of students participating in the program.

\section{Results}

The composition of the final sample was 58 male and female students between the ages of 18 and 64 . The sample for the control group $(\underline{n}=33)$ exceeded the desired number of 30 , even though 7 students did not attend their class on the appropriate day to complete the posttest. Test results from one student were omitted due to the student's seif-reported age of 17 .

The expected sample size of 30 for the massage group was not met $(\underline{n}=25)$. The following factors accounted for this:

1) Some students were never available at the phone number provided.

2) Difficulties were encountered in making contact with students by phone. If students were not contacted in adequate time prior to their massage appointment, too few opportunities existed to set up an appointment for the pretest. When students were contacted too far in advance of their massage appointment, it increased the risk of forgetting their pretest appointment. On four occasions, students failed to keep their pretest appointment and 
realized this at the time of their massage appointment.

3) One student did not keep the massage appointment, and subsequently did not complete the posttest.

4) One student became physically ill during the massage (due to the flu) and left without completing the posttest.

Despite these difficulties, all students who were asked to participate in the study did agree to do so except for three students. These three students, one from the control group and two from the massage group, voluntarily admitted that they participated in a weekly off-campus massage program and felt they would not be able to be objective participants in this study.

Demographic data for the two groups showed that participants were a representative sample of this community college's student population. Table 1 showed the mean age and work status of both groups.

Table 1

Age. Sex. Work Status of Participants $(N=58)$

\begin{tabular}{lllllll}
\hline & & $\begin{array}{l}\text { Mean } \\
\text { Age } \\
\text { (years) }\end{array}$ & M & F & $\begin{array}{l}\text { Full-time } \\
\text { Student (\%) }\end{array}$ & $\begin{array}{l}\text { Part-time } \\
\text { Students } \\
\text { Who Work (\%) }\end{array}$ \\
\hline Massage & 25 & 37 & 8 & 17 & 44 & 56 \\
Control & 33 & 27 & 15 & 18 & 21 & 79 \\
\hline
\end{tabular}

These findings are consistent with the college's demographics which 
reveal a female majority of $54 \%$. At this particular college, the student population is older than that of other California Community Colleges with a majority of students in the 25-49 age group (45\%) and with a greater majority of part-time, working students (74\%) (California Community Colleges, 1987).

\section{Extraneous Variables}

"Extraneous variables are variables that interfere with the operations of the phenomena being studied" (LoBiondo-Wood \& Haber, 1986, p. 105). Before discussing the results of this study, the effect of extraneous variables has to be considered. The use of consistent data collection procedures and controlling the manipulation of the independent variable are two means of controlling the effect of extraneous variables (LoBiondo-Wood \& Haber, 1986, p. 105).

The time interval between administration of the pretests and posttests in the massage group was the only aspect of the data collection procedure that varied between the two groups. Massage appointments were spread through a five-week time period. Due to scheduling conflicts of work and school of the researcher and participants, the interval of pretest and posttest administration could not be kept constant. All pretest and posttests were administered within a one-week interval, as were the tests in the control group.

During the course of this study, the Massage Therapy Program was staffed by three certified massage practitioners, one male and two female. To decrease the concern of any inconsistent manipulation of the independent 
variable, the massage therapists performed evaluation massages on each other prior to the start of the study and determined that their massage technique was similar. Also, all three therapists were graduates of the same massage therapy school, further strengthening the control of this extraneous variable.

\section{Trait Anxiety}

A baseline similarity of the two groups was established using the Trait Anxiety of the STAI. This set of questions in the index was designed to indicate an individual's tendency toward anxiety. It was important to establish that all participants were similar in their tendency toward anxiety in order for any decrease in the State scores of the massage to be of any significance. As seen in Table 2, the f-test for independent samples supported that there was no significant difference in the mean trait anxiety scores between the massage and the control groups $(t(56)=.80, \underline{p}<.430)$. To confirm the reliability of the STAI with this population, the mean Trait scores were compared with the published norms and were found to be in an acceptable range (Appendix B). 
Table 2

\section{Experimental and Control Group Mean Trait Anxiety Scores}

$\underline{N=58)}$

\begin{tabular}{llllll}
\hline Group & n & $\begin{array}{l}\text { Mean Trait } \\
\text { Score }\end{array}$ & SD & df & t value \\
\hline Massage & 25 & 39.9 & 8 & 56 & .80 \\
Control & 33 & 38.1 & 9 & & \\
\hline
\end{tabular}

Note: Minimum possible trait score $=20$; maximum possible trait score $=80$. 
State An:xiety

An important variable that may influence the posttest anxiety scores is an original difference in pretest anxiety scores of both groups. Table 3 shows the scores of the massage and control groups. According to the STAI manual (1983), pretest State scores should match closely with the Trait scores when given under normal conditions (State scores should be lower than Trait scores when given in very relaxed conditions, and be higher than Trait scores when given in high-anxiety situations). In this study, the State Anxiety pretest was given under normal conditions and closely matched pretest Trait Anxiety scores.

Table 3

Experimental and Control Group Mean Pretest

State Anxiety Scores ( $N=58)$

\begin{tabular}{lccc}
\hline Group & $\mathrm{n}$ & $\begin{array}{c}\text { Mean Pretest } \\
\text { State Anxiety Scores }\end{array}$ & SD \\
\hline Massage & 25 & 39 & 12 \\
Control & 33 & 39 & 11 \\
\hline
\end{tabular}




\section{The Hypotheses and The Results}

The t-test on the gain scores for these independent samples was used to test the following hypotheses: 1) students participating in a massage therapy program and attending classes will demonstrate lower anxiety levels after massage than before massage, and 2) students enrolled in courses and not participating in the massage program will not demonstrate a significant change in anxiety levels. Table 4 showed that the posttest scores of the control group remained unchanged from pretest scores, and that the posttest scores of the massage group were lower than the pretest scores. This data was further analyzed using the t-test on the gain scores of the two groups to compare the changes in the posttest State anxiety scores $(I(56)=4.51, \mathrm{~g}<.001)$. All of the above hypotheses were supported, and, the difference between the mean gain scores of the two groups reached a statistically significant level. 
Table 4

Experimental and Control Group Mean Posttest State

Anxiety Scores ( $N=58)$

\begin{tabular}{lccccc}
\hline Group & n & $\begin{array}{c}\text { Mean Posttest } \\
\text { State Anxiety } \\
\text { Scores }\end{array}$ & SD & $\begin{array}{c}\text { Mean Gain } \\
\text { (pretest minus } \\
\text { posttest score) }\end{array}$ & Ivalue \\
\hline Massage & 25 & 27 & 6 & -11.8 & $4.51^{\star}$ \\
Control & 33 & 39 & 9 & .5 & \\
\hline
\end{tabular}

Note: Minimum possible anxiety score $=20$; maximum possible anxiety score $=80$.

${ }^{\star} \mathrm{R}<.001$ 


\section{Chapter 5}

\section{CONCLUSIONS AND RECOMMENDATIONS}

This chapter first presents the conclusions of this research study.

Recommendations are made for further research. Implications for nursing's role in the community health education setting are discussed.

\section{Conclusions}

The results of this study suggest that massage is an effective stress intervention for the students who participate in the program. College students, whether they are younger 18 to 22 -year-old students facing developmental changes, or older students working, raising a family, and furthering their education simultaneously, are at risk for stress reactions. The need for the control of stress was supported in the literature. High levels of anxiety, a negative psychological aspect of stress, have been shown in the literature to affect academic performance. In this study, a one-hour body massage has been shown to significantly lower anxiety levels.

The massage therapy program provides one stress reduction option for the students who thought they could individually benefit from it. The intent was not to promote massage as the only form of stress reduction.

The demographic data analysis showed that those who used this massage program were predominantly older students, who were working while going to school. The majority of the participants were women. The profile of the student 
group attracted to massage as a form of stress reduction is similar to the student profile of the community college. The demographic data from the study is invaluable as it will assist in the assessment and implementation of additional stress reduction programs with similar or different target populations.

\section{Recommendations}

The process of conducting this study generated additional suggestions for further research. These recommendations would improve the credibility of the hypothesis that was tested in this project.

1. Replicate this study using greater time controls between administration of the pretest and posttests, which will provide additional means of controlling extraneous variables.

2. Replicate the study changing the procedure of administration of the posttest so that it is not administered by the massage therapist. This might eliminate the effect of "social desirability." Although the massage therapist left the room while the student completed the anonymous test, having a third party participate in this phase would decrease the possibility of this concern.

3. Replicate this study using a population of students who are interested in a stress reduction program utilizing massage, and drawing a randomized sample from this population. (A truly randomly drawn sample for this particular type of research probably would not be beneficial. The Health Services promotes many programs with the belief that each student will find a suitable 
program to meet his/her needs. It is not the goal of this department to encourage any student to participate in a program in which the student may feel uncomfortable. If the study was to be replicated using a truly randomly selected sample, a touch-aversion study would need to be done first, to eliminate those participants who do not like to be touched.)

4. Replicate this study only using part-time students who work, which would permit greater generalization to other working populations.

5. Replicate the study administering the posttests at different intervals following the massage (i.e. immediately, 24 hours, 48 hours) in an attempt to evaluate the student's response to the massage in maintaining the decreased anxiety levels.

6. Replicate this study placing greater controls on antecedent variables, such as socioeconomic status and health status, in an attempt to evaluate any impact of these variables on anxiety states of participants.

7. Replicate the study adding one physiological measurement at a time. This will provide a greater knowledge base regarding the mechanism(s) by which massage achieves lower anxiety levels in participants.

$$
\text { Implications for Nursing Practice }
$$

Community health nursing is concerned with primary prevention and health promotion of individuals, families, groups, and the community. The systematic process of assessment, planning, implementation and evaluation is 
used by nursing in order for the client to achieve the maximum level of wellness. Neuman's Systems Model provides community health nurses with a guide to develop health promotion programs. This program was implemented following a needs assessment for a stress reduction program. The basis for this program was supported in the literature. The need for stress management has been identified by college educators and the Surgeon General, as well as by college students. The need to strengthen this population's flexible lines of defense against the stressors of everyday life provided the theoretical underpinnings that led to the choice of this particular primary prevention program.

The message for nursing is that evaluation is a critical component of the needs assessment process. "The purpose of evaluation is always that of determining the worth or value of something" (Neuman, 1982, p. 77). Recently, there has been increased interest placed on the evaluation of health services due to increased costs of health care. However, the primary purpose of evaluating health promotion programs is to determine whether and how well the objectives are being met.

The intent of this project was to evaluate ihe effectiveness oi a massage therapy program on the perceived stress levels of college students. The results of this study showed that massage significantly lowered anxiety levels, a negative aspect of stress, in the students who participated. Thus, the massage 
program has been proven to be an appropriate primary prevention program on this campus. And as a result of this evaluation research, reliable data has been added to the knowledge base concerning massage and its psychological benefits, paving the way for additional research and the implementation of similar massage programs. 
REFERENCES 


\section{References}

Bevis, E.M. (1982). Curriculum building in nursing, a process. St. Louis: The C.V. Mosby Company.

California Community Colleges. Research and Analysis Unit. (1987). Report on Enrollment. Sacramento: California Community Colleges, Office of the Chancellor, Research and Analysis Unit.

Chervin, D., Sloane, B., Gordon, K., and Gold, R. (1986). Achieving the health objectives for the nation in higher education. College Health, $35,15-20$.

County of Santa Clara, Advanced Planning Office. (1988). [Info: Profile of projected growth in Santa Clara County]. Unpublished raw data.

Day, J., Mason, R., and Chesrown, S. (1987). Effect of massage on serum level of B-Endorphin and B-Lipotropin in healthy adults. Physical Therapy, 67 (6), 926-929.

Foothill College Student Health Services. (1989). [Survey of student health interests.] Unpublished raw data.

Freiberg, K. (1979). Human development. North Scituate: Massachusetts: Duxburg Press.

Guyton, R., Corbin, S., Zimmer, C., O'Donnell, M., Chervin, D., Sloane, B., Chamberlain, M. (1989). College students and national health objectives for the year 2000: A summary report. Journal of American College Health, 38, 9-14. 
Health Services Association of California Community Colleges (1987). Siujdent services manual. Unpublished manuscript.

Hendricks, C., and Young, M. (April/May, 1986). Assessing student health interests. Health Education, pp. 45-46.

Kaufman, M. (1964). Autonomic responses as related to nursing comfort measures. Nursing Research, 13 (1), 45-55.

Krusen, F. (1966). Handbook of physical medicine and rehabilitation.

Philadephia: W.B. Saunders Company.

Lazarus, R. (1963). Personality and adjuștment. Englewood Cliffs, New Jersey: Prentice-Hall, Inc.

Lazarus, R. (1966). Psychological stress and the coping process. New York: McGraw Hill Cook Company, Inc.

Lazarus, R., Folkman, S. (1984). Stress, Appraisal and Coping. New York: Springer Publishing Company.

LoBiondo-Wood, G., Haber, J. (1986). Nursing research. St. Louis: The C. V. Mosby Company.

Longworth, J. (1982). Psychophysiological effects of slow stroke back massage in normotensive females. Advances in Nursing Science, 1 (4), 44-60.

Marriner, A. (1986). Nursing theorists and their works. St. Louis: C.V. Mosby Company. 
Neuman, B. (1972). A model for teaching total person approach to patient probiems. Nursing Research, 21 (3), 264-268.

Neuman, B. (1982). The Neuman systems model. Norwalk, Connecticut: Appleton-Century-Crofts.

Spielberger, C. (1983). Manual for the state-trait anxiety inventory. Palo Alto, CA.: Consulting Psychologists Press.

Spielberger, C. (1962). The effects of manifest anxiety on the academic achievement of college students. Mental Hygiene, 46, 420-26.

Tobias, R. (1984). Effect of massage on a three mile nun. Unpublished master's thesis, San Jose State Universiiy, San Jose, CA.

U.S. Department of Commerce, Bureau of the Census, USA Statistics in Brief 1988. Washington, D.C., 1988.

U.S. Department of Health and Human Services. (1987). National trends in druguse and related factors among American high school students and young adults, 1975-1986. National Institute on Drug Abuse, Rockville, MD. 


\section{APPEND!XES}

49 


\section{APPENDIX A \\ Sample of State Trait Anxiety Inventory \\ Evaluation Questionnaire}

Note: Permission to reproduce this tool in its entirety was not given. This sample was adapted and reproduced by special permission of the Publisher, Consulting Psychologists Press, Inc., Palo Alto, CA. 94306. 
SAMPLE ITEMS FROM THE STATE-TRAIT ANXIETY INVENTORY

\section{$\underline{Y-1 \text { (State portion) }}$}

1. NOT AT ALL

2. SONEWHAT

3. MODERATELY SO

4. VERY MUCH SO

I feel calm

I feel secure

I am tense

\section{Y-2 (Trait portion)}

1. ALMOST NEVER

2. SOMETIMES

3. OFTEN

4. ALMOST ALWAYS

I feel pleasant

I feel nervous and restless

I feel satisfied with myself

Please do not present these items to your readers as any kind of mini-test, but only as an illustrative sample of items from this instrument. He have provided these items as samples in order that we may maintain some measure of control over the items which appear in any published media. The reason for this control is to avoid having the instrument appear in its entirety, or in segments that may be pieced together to form an entire working instrument, aliowing access to the instrument by unqualified individuals.

Thank you for your cooperation. 


\section{APPENDIX B}

Means, Standard Deviations, and Alpha Coefficients

\section{For College Students}


Means. Standard Deviations, and Alpha Coefficients for College Students

$(N=855)$

$\begin{array}{ll}\text { Male } & \text { Female } \\ (\underline{n}=324) & (\underline{n}=521)\end{array}$

State Anxiety

$\begin{array}{lrr}\text { mean } & 36.47 & 38.76 \\ \text { SD } & 10.02 & 11.95 \\ \text { alpha } & .91 & .93\end{array}$

Trait Anxiety

$\begin{array}{lrr}\text { mean } & 38.30 & 40.40 \\ \text { SD } & 9.18 & 10.15 \\ \text { alpha } & .90 & .91\end{array}$

Note: From Manual for the State-Trait Anxiety Inventory (p. 5) by D.

Spielberger, 1983, Palo Alto, California: Consulting Psychologists Press, Inc. Copyright 1983 by Consulting Psychologists Press, Inc. Reprinted with permission. 


\title{
APPENDIX C
}

\section{Approval By Human Subjects}

\author{
Institutional Review Board
}




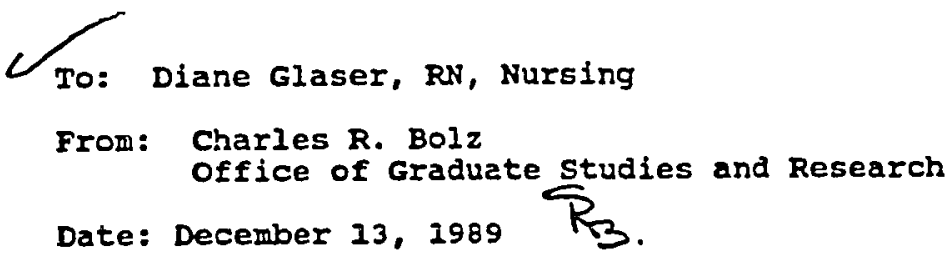

The Human Subjects Institutional Review Board has approved your request to use buman subjects in the study entitled:

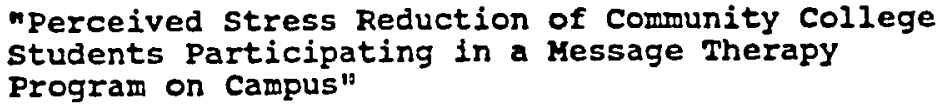

This approval is contingent upon the subjects participating in your research project being appropriately protected from risk. This includes the protection of the anonymity of the subjects' identity when they participate in your research project, and with regara to any and all data that may be collected from the subjects. The Board's approval includes continued monitoring of your research by the Board to assure that the subjects are being adequately and properly protected from such risks. If at any time a subject becomes injured or complains of injury, you must notify Dr. Serena stanford immediately. Injury includes but is not limited to bodily harm, psychological trauma and release of potentially damaging personal information.

Please also be advised that each subject needs to be fully informed and aware that their participation in your research project is voluntary, and that he or she may withdraw from the project at any time. Further, a subject's participation, refusal to participate or withdrawal will not affect any services the subject is receivirg or yill receive et the institution in which the research is being conducted.

If you have any questions, please contact Dr. Stanford or me at $4-2480$.

cc: Emilie Musc1, Ph.D. 


\section{APPENDIX D \\ Foothill College Approval \\ by Vice-President Student Services}


Olfice of the Dean Siscen: Se'vice: Pnone 4 is c $0 \leqslant-4: 28$

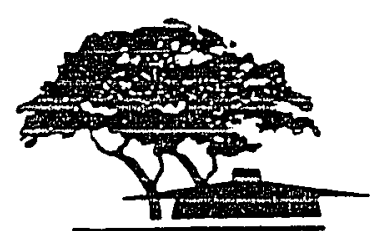

FOOTHILL
COLLEGE

October 13, 1989

\section{TO WHOM IT MAY CONCERN:}

I am writing this letter on behalf of Diane Glaser, RN, who has requested permission to conduct a research study on the Foothill Campus entitled, the Perceived Stress Reduction of Community College Students Participating in a Massage Therapy Program on Campus during Winter Quarter 1990.

It is my understanding that the results of this study will increase the knowledge of practitioners in the area of stress management with the community college student population and provide an eviluation of the effectiveness of the existing massage therapy program.

I also understand that Foothill's participation in this study is voluntary and therefore give Diane permission to conduct this study as requested.

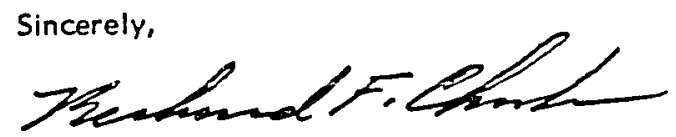

Richard F. Charles

Vice President

RFC/ne

Student Services

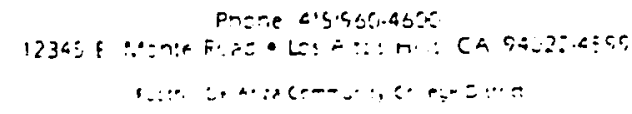




\section{APPENDIX E}

Consent Form for Experimental Group

Consent Form for Control Group 
School of the Apolled Arte and Sctencere. Dopurtment of Nuralm

One Washington Square - San Jose. Calitomia 95192-0057 -408/924-3130

\section{Agreement to Participate in Research}

\section{RESPONSIBLE DNVESTIGATOR: Diane Glaser}

Title of Protocol: The Perceived Stress Reduction of Community College Students Participating in a Massage Therapy Program on Campus

I have been asked to participare in a research study that is investigating the effects of massage on college students. The results of this study should further our understanding of the students' perception of the effects of massage.

I understand that

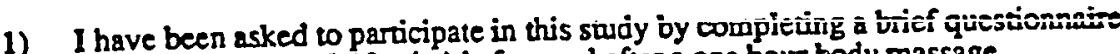
(approximate time 6-10 min.) before and afier a one hour body massage.

2) Massage is not considered to be a high-risk procedure; however, there is a possibility of mild muscle soreness following the massage. An attempt to minimize this possibility will be made by asking the subjects to inform the massage practitioner of any discomfor noticed during the massage.

3) The possible benefit to me is an increased exposure to an existing health promotion program on campus, as well as an increased feeling of well-being due to the stress reduction, relaxation effect of massage.

An additional benefit to me is the experience of actively participating in research and being included in the sharing of the results.

4) The results from this study may be published, but no information from the study can be identified with me. The questionnaire is anonymous, so confidentiality is assured.

5) Any questions about my participation in this study will be answered by Diare Glaser, who can be reached at (415) $949-7243$. Complaints about the procedures may be presented to Dr. E. Musci at (408) 924.3152 . For questions or complaints about research subject's rights, or in the event of research-related injury, contact Serena Stanford, $\mathrm{PhD}$. (Associate Academic Vice-President fo: Graduare Srudies and Research) at (408) 924-2480.

6) My consent is given voluntarily sithout being coerced; I may refuse to participate in any part of this study, and I may withdraw at any time, without prejudice :o my relations with SJSU or Foothill College.

7) I have received a copy of this consent for my file.

I have made my decision whether or not 10 participate. My signature indicates that I have decided to participate, having read the above information.

\section{Dale}

Participant's signature 


\section{Agreement to Participate in Research}

RESPONSIBLE INVESTIGATOR: Diane Glaset

\section{Titie of Protocol: The Perceived Stress Reduction of Community College Srudents Participating in a Massage Therapy Program on Campus}

I have been asked to paricipate in a research study that is investigating the effects of massage on college students. The results of this study should further our understanding of the students' perception of the effects of massage.

I understand that

1) I have been asked to participate as a member of the control group in this study by completing a brief questionnaire (approximate time 6-10 min.) before and after atrendance in a regularly scheduled general education course.

Title of Course:

2) Toe benefits of participating in this study include the experience of participating in research, being exposed to a stress management program on campus, and being included in the sharing of the results of the study.

3) The possible risk of this study, as a member of the control group, include mild discomfort that may be felt as a result of invasion of privacy due to answering the questions on the questionnaire as turthfully as possible.

4) The results from this study may be published, but no information from the study can be identified with me. The questionnaire is anonymous, so confidentiality is assured.

5) Any questions about my paricipation in this study will be answered by Diane Glaser, who can be reached at (415) 949-7243. Complainis about the procedures may be presented to Dr. E. Musci at (408) 924-3152. For questions or complaints about research subject's rights, or in the event of iesearch-related injury, contact Serena Stanford, Ph.D. (Associate Academic Vice-President for Graduate Studies and Research) at (408) 924-2480.

0) My consent is given voluntarily without being coerced; I may refuse to participate in any pars of this study, and I may withdraw at any time, without prejudice to my relarions with SISU or Foothill College.

7) I have received a copy of this consent for my file.

I have made my decision whether or not to paricipate. My signature indicates that I have decided to participate, having read the sbove injurmation.

\section{Date}

Participant's signature

Livestigator's signature 